\title{
Comments on "the Kuroshio intermediate water is the major source of nutrients on the East China Sea continental shelf" by Chen (1996)
}

\author{
Kon-Kee LIU \\ Institute of Oceanography, National Taiwan University, P.O. Box 23-13, Taipei, Taiwan, Republic of China \\ kkliu@ccms.ntu.edu.tw
}

(Received 15/01/98, revised 09/06/98, accepted 17/06/98)

\begin{abstract}
Chen estimated (Oceanol. Acta 19, 1996) the influxes of water and nutrients from the Kuroshio to the East China Sea shelf separately for the wet and dry periods within a year, based on a steady-state box model. This approach is demonstrated to be flawed in terms of both mathematical rigor and observational evidence. A time-dependent term must be included in the model calculation, if intra-annual variation is to be determined. $(\odot)$ Elsevier, Paris
\end{abstract}

\section{East China Sea / Kuroshio / box model / water transport / non-steady state}

Résumé - Commentaire sur « L'eau intermédiaire du Kuroshio, principale source de nutriments sur le plateau continental de la mer de Chine orientale » par Chen (1996). Chen a estimé (Oceanol. Acta 19, 1996) les apports d'eau et de nutriments du Kuroshio sur le plateau continental de la Mer de Chine orientale, séparément pour les périodes sèche et humide, au cours d'une année, avec un modèle en bô̂te stationnaire. Cette approche présente des défauts, dans la rigueur mathématique comme dans l'observation. Un terme de dépendance temporelle doit y être introduit pour déterminer la variabilité intra-annuelle. ㅇ Elsevier, Paris

Mer de Chine orientale / Kuroshio / modèle en boîte / transport d'eau / état non stationnaire

Marginal seas are gaining increasing attention due to their high primary productivity and active biogeochemical processes $[12,14]$. In order to understand the significance of these environments on a global scale, there is a need to quantify their biogeochemical fluxes. Responding to that need, Chen [2] estimated nutrient influxes from Kuroshio waters to the East China Sea shelf, based on a box model of salt and water balance (figure 1). The domain of the model, including the contiguous shelves of the East China Sea, Yellow Sea and the Bohai Bay, has a total area of $1.24 \times 10^{6} \mathrm{~km}^{2}$, about 1/30 of the global shelf area. Two of the world's largest rivers, the Changjiang and the Yellow River, discharge into this region. Upwelling of the Kuroshio water from a depth of 200-300 m off northeastern Taiwan provides a rich supply of nutrients for the shelf [16]. The vast expanse and the strong nutrient sources make this region especially interesting for biogeochemical studies of continental margins [8]. Due to the seasonal fluctuation of runoff and the alternating monsoonal systems, this region is subject to strong seasonal forcing.

In an attempt to resolve the seasonal contrast, Chen [2] calculated the cross-shelf transports for the wet period (May-October) and the dry period (November-April) separately under a steady-state assumption. The calculation yields a surprising result: influxes of water and nutrients from the Kuroshio are much smaller during the dry period, when the prevailing northeast monsoon favours Kuroshio intrusion [1], than during the wet period, when the prevailing wind reverses. In light of the strong intraannual variation on the continental shelf, the steady state assumption appears to be an unsound premise for Chen's semi-annual budget calculation. 


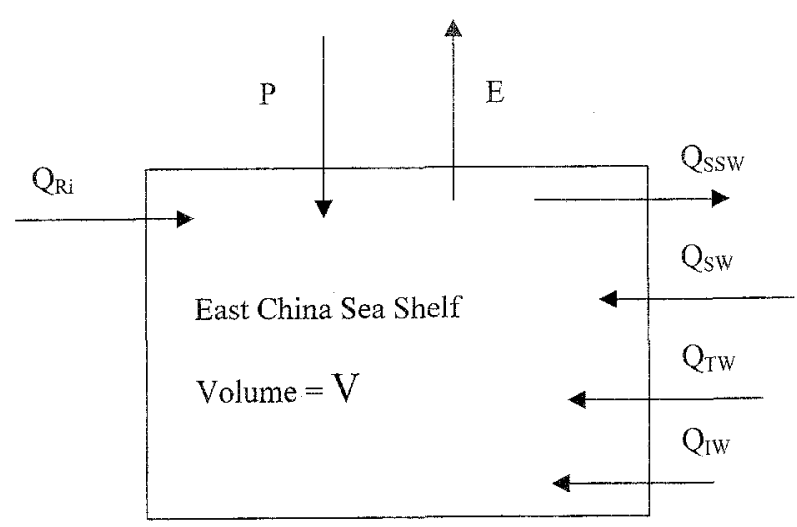

Figure 1. The box model for water balance on the East China Sea shelf proposed by Chen (1996). The Qs are transports of seawater in $\mathrm{km}^{3} \mathrm{yr}^{-1}$ with the subscripts denoting different water types: $\mathrm{Ri}=$ river water; $\mathrm{SSW}=$ shelf surface water; $\mathrm{SW}=$ Kuroshio surface water; TW = Kuroshio tropical water; and IW = Kuroshio intermediate water. $\mathrm{P}$ and $\mathrm{E}$ stand for precipitation and evaporation, respectively.

Following Gordon et al. [7], a conservative tracer (C) in a volume $(\mathrm{V})$ is governed by:

$\mathrm{d}(\mathrm{VC}) / \mathrm{dt}=\Sigma \mathrm{Q}_{\mathrm{in}} \mathrm{C}_{\mathrm{in}}-\Sigma \mathrm{Q}_{\text {out }} \mathrm{C}_{\text {out }}$,

where $\mathrm{Q}_{\mathrm{in}}$ and $\mathrm{Q}_{\text {out }}$ represent hydrographic inflows and oufflows in volumetric units, and $\mathrm{C}_{\text {in }}$ and $\mathrm{C}_{\text {out }}$ are volumetric tracer concentrations.

For the East China Sea shelf, Chen [2] included inputs from the Kuroshio intrusion $\left(Q_{K}\right)$, riverine discharge $\left(\mathrm{Q}_{\mathrm{Ri}}\right)$, and precipitation $(\mathrm{P})$. He divided the Kuroshio intrusion into three components; the surface water $\left(Q_{S W}\right)$, the tropical water $\left(\mathrm{Q}_{\mathrm{TW}}\right)$ and the intermediate water $\left(Q_{I W}\right)$. His outputs included the shelf surface water outflow $\left(\mathrm{Q}_{\mathrm{SSW}}\right)$ and evaporation $(\mathrm{E})$. If $\mathrm{V}$ is constant and $\mathrm{S}_{\mathrm{Sh}}$ denotes mean shelf water salinity, Equation (1) can be expressed as:

$\mathrm{V}\left(\mathrm{d} \rho_{\mathrm{Sh}} \mathrm{S}_{\mathrm{Sh}} / \mathrm{dl}\right)=\rho_{\mathrm{SW}} \mathrm{Q}_{\mathrm{SW}} \mathrm{S}_{\mathrm{SW}}+\rho_{\mathrm{TW}} \mathrm{Q}_{\mathrm{TW}} \mathrm{S}_{\mathrm{TW}}$

$+\rho_{I W} Q_{I W} S_{I W}+\rho_{R i} Q_{R i} S_{R i}-\rho_{S S W} Q_{S S W} S_{S S W}$,

where the $\rho$ factors denote densities $\left(\mathrm{kg} \mathrm{dm}^{-3}\right)$ of various water types, which are needed to convert salinity from gravimetric concentration $\left(\mathrm{g} \mathrm{kg}^{-\mathrm{l}}\right)$ to volumetric concentration $\left(\mathrm{g} \mathrm{dm}^{-3}\right)$. Chen [2] ignored the density terms and presumed the left-hand side of Equation (2) to be zero. Replacing the density terms by 1 causes minor errors (usually less than $1 \%$ under steady state conditions), but neglecting the time-derivative term may lead to errors of more than $100 \%$ in the intra-annual fluxes (see later dis. cussion).

Aside from salt balance, Chen [2] employed the wates balance equation for his calculation:

$\mathrm{Q}_{\mathrm{SW}}+\mathrm{Q}_{\mathrm{TW}}+\mathrm{Q}_{\mathrm{IW}}+\mathrm{Q}_{\mathrm{Ri}}+\mathrm{P}-\mathrm{Q}_{\mathrm{SSW}}-\mathrm{E}=0$.

Making use of his previous observations on one hydrographic transect northeast of Taiwan in September 1988 and December 1989 [3], he calculated volume transports and nutrient fluxes for the two contrasting periods. The input values for the calculation are given in the upper part of table $I$; the calculated total inflows from the Kuroshio are given at the bottom.

Table I. Some of the inputs and outputs of Chen's (1996) box model.

\begin{tabular}{lcc}
\hline & $\begin{array}{c}\text { Wet period } \\
\text { (May-October) }\end{array}$ & $\begin{array}{c}\text { Dry period } \\
\text { (November-April) }\end{array}$ \\
\hline Inputs: values used for calculation & \\
\hline $\mathrm{Q}_{\mathrm{Rj}}\left(\mathrm{km}^{3} / 6 \mathrm{mon}\right)$ & 813 & 404 \\
$\mathrm{P}-\mathrm{E}\left(\mathrm{km}^{3} / 6 \mathrm{mon}\right)$ & 420 & -280 \\
$\mathrm{Q}_{\mathrm{SW}}: \mathrm{Q}_{\mathrm{TW}}: \mathrm{Q}_{\mathrm{IW}}$ & $3: 1.5: 1$ & $8: 3: 1$ \\
$\mathrm{~S}_{\mathrm{SW}}$ & 34.5 & 34.5 \\
$\mathrm{~S}_{\mathrm{TW}}$ & 34.9 & 34.9 \\
$\mathrm{~S}_{\mathrm{IW}}$ & 34.3 & 34.3 \\
$\mathrm{~S}_{\mathrm{Ri}}$ & 0.18 & 0.18 \\
$\mathrm{~S}_{\mathrm{SSW}}$ & 33.1 & 33.8 \\
\hline
\end{tabular}

Outputs: calculated inflows from Kuroshio

\begin{tabular}{lll}
\hline $\mathrm{Q}_{\mathrm{K}}\left(\mathrm{km}^{3} / 6 \mathrm{mon}\right)$ & 27360 & 5260 \\
\hline
\end{tabular}

The most striking result of Chen's calculation was the diminished Kuroshio intrusion during the dry period. The estimated volume of transport for the dry period was only 1/5 of that for the wet period. Moreover, Chen [2] attributed the higher salinity in shelf waters during the dry period to the lower runoff. However, current measurements and repeated hydrographic surveys do not support such conclusions. Based on observations from moored current meters and Acoustic Doppler Current Profilers, Tang and Yang [15] and Chuang and Liang [4] reported that the Kuroshio surface flow intruded onto the Fast China Sea shelf starting in mid-October and ending in mid-May. Physical and chemical hydrography as well as numerical modelling lend further support to the winter intrusion $[1,6,9]$. Besides surface intrusion, subsurface intrusion by the Kuroshio water, often called Kuroshio upwelling, has also been widely observed. A long hydro- 
graphic record suggests that it occurs throughout the year and serves as a strong nutrient source $[5,11]$, which was unfortunately overlooked by Chen [2].

Going back to the basic equations, the three components of Kuroshio intrusion are recombined into $\mathrm{Q}_{\mathrm{K}}$ and it is solved using Equations (2) and (3). The solution is:

$$
\begin{aligned}
Q_{K}= & {\left[Q_{R i}\left(\rho_{S S W} S_{S S W}-\rho_{R i} S_{R i}\right)+(P-E) \rho_{S S W} S_{S S W}\right.} \\
& \left.+V\left(d \rho_{S h} S_{S h} / d t\right)\right] /\left(\rho_{K} S_{K}-\rho_{S S W} S_{S S W}\right)
\end{aligned}
$$

where $S_{K}$ and $\rho_{K}$ are the mean salinity and density of the Kuroshio water, which are 34.59 and $1.024 \mathrm{~kg} \mathrm{dm}^{-3}$ for the wet period and 34.58 and $1.02 .5 \mathrm{~kg} \mathrm{dm}^{-3}$ for the dry period. The three terms in the numerator on the right hand side of Equation (4) are evaluated and listed in table II. The value of $\left(\mathrm{d}_{\mathrm{Sh}} \mathrm{S}_{\mathrm{Sh}} / \mathrm{dt}\right)$ is calculated as the mean change rate of the total salt content on the shelf between the wet and the dry periods. The shelf water is assumed to consist of equal amounts of surface water and bottom watcr. The former is assumed to have different salinities (33.1 and 33.8) and temperatures ( 25 and $19^{\circ} \mathrm{C}$ ) for the wet and dry seasons, whereas the latter is assumed to have constant salinity and temperature. The volume of the system is $45000 \mathrm{~km}^{3}$. Then, the mean value of $\mathrm{V}\left(\mathrm{d} \rho_{\mathrm{Sh}} \mathrm{S}_{\mathrm{Sh}} / \mathrm{dt}\right)$ is negative, -17.8 (Gt/6 months), for the wet period, during which salinity decreases with time, and positive for the dry period, during which the salinity increases. The comparison shown in table $I I$ makes it clear that the $\mathrm{V}\left(\mathrm{d} \rho_{\mathrm{Sh}} \mathrm{S}_{\mathrm{Sh}} / \mathrm{dt}\right)$ term is too important to be neglected.

Table II. Evaluation of terms in the numerator on the right hand side of Equation (4).

\begin{tabular}{lcc}
\hline $\begin{array}{l}\text { Terms } \\
(\text { Gt/6 mon) }\end{array}$ & $\begin{array}{c}\text { Wet period } \\
\text { (May-October) }\end{array}$ & $\begin{array}{c}\text { Dry period } \\
\text { (November-April) }\end{array}$ \\
\hline $\mathrm{Q}_{\mathrm{Ri}}\left(\rho_{\mathrm{SSW}} \mathrm{S}_{\mathrm{SSW}}-\rho_{\mathrm{Ri}} \mathrm{S}_{\mathrm{Ri}}\right)$ & 27.3 & 13.9 \\
$(\mathrm{P}-\mathrm{E}) \rho_{\mathrm{SSW}} \mathrm{S}_{\mathrm{SSW}}$ & 14.2 & -9.7 \\
$\mathrm{~V}\left(\mathrm{~d} \rho_{\mathrm{Sh}} \mathrm{S}_{\mathrm{Sh}} / \mathrm{dt}\right)$ & -17.8 & 17.8 \\
\hline
\end{tabular}

Inclusion of the $\mathrm{V}\left(\mathrm{d} \rho_{\mathrm{Sh}} \mathrm{S}_{\mathrm{Sh}} / \mathrm{dt}\right)$ term in the calculation using Equation (4) gives values of inflow from the Kuroshio: $14619 \mathrm{~km}^{3} / 6$ months for the wet period and $26388 \mathrm{~km}^{3} / 6$ months for the dry period. These values are qualitatively consistent with other observations, but contrary to Chen's [2] seasonal estimates. His transport for the wet season could be too high by a factor of 2 , and that for the dry season too low by a factor of 5 .
It is cautioned that these estimated semi-annual transports should not be taken at their face value in spite of the qualitative agreement with observations, because they are sensitive to the time-derivative term. A more comprehensive database is needed for an accurate evaluation of it. The sensitivity of the calculation to the time-derivative term is illustrated here. Equation (4) shows that the timederivative controls the value of $\mathrm{Q}_{\mathrm{K}}$ with a coefficient, $V /\left(\rho_{K} S_{K}-\rho_{S S W} S_{S S W}\right)$, where $V$ is a constant $\left(45000 \mathrm{~km}^{3}\right)$ and the denominator has a value of $1.625 \mathrm{~g} \mathrm{dm}^{-3}$ for the wet period and $0.833 \mathrm{~g} \mathrm{dm}^{-3}$ for the dry period. The timederivative may be expressed as:

$\left(d \rho_{S h} S_{S h}\right) / d t=\rho_{S h} d S_{S h} / d t+S_{S h} d \rho_{S h} / d t$

The two terms on the right hand side usually have the same sign on the East China Sea shelf, because the salinity increase is often accompanied by a temperature drop, and, hence, a density increase during transition from the wet to the dry period. Consequently, for a salinity change of 0.1 in 6 months, the mean rate of change in volumetric salt concentration, $\left(\mathrm{d} \rho_{\mathrm{Sh}} \mathrm{S}_{\mathrm{Sh}}\right) / \mathrm{dt}$, is usually larger than $0.1 \mathrm{~g} \mathrm{dm}^{-3} / 6$ months. Then, the change in $\mathrm{Q}_{\mathrm{K}}$ would be larger than $2769 \mathrm{~km}^{3} / 6$ months for the wet period and $5403 \mathrm{~km}^{3} / 6$ months for the dry period, indicating that the transport of the dry period is more sensitive to the timederivative term than that of the wet period. The significance of the time-derivative term simply reflects the fact that the residence time of fresh water on the shelf is comparable or longer than the time scale of interest, i.e. 6 months. The fraction of fresh water in the shelf water during dry season is not solely attributed to the fresh water input during that period of time, but also to the remaining fresh water from the wet period. The fraction of fresh water in the shelf surface water during the wet season is calculated to be $4.3 \%$ for a two-end member mixing of the fresh water and the Kuroshio water with a salinity of 34.59. The fraction of remaining fresh water in the shelf surface water would be $3.3 \%$ if the shelf were flushed by a constant Kuroshio inflow without any fresh water input. The constant Kuroshio inflow is calculated from the mean shelf water residence time of two years [13]. The predicted fraction of the remaining fresh water is higher than the actual value $(2.0 \%)$ calculated from the salinity of the dry period. This unlikely result indicates that an increase in Kuroshio inflow during the dry period is required to bring down the fresh water fraction or to raise the salinity to the observed levels. This implication is exactly what was predicted by the calculation shown above. 
On the uther hand, the time-derivative of salinity may become negligible for the annual budgeting, because the inter-annual variation of shelf water salinity is expected to be much smaller than the intra-annual variation. Therefore, the steady-state approach to the water and salt balance becomes more acceptable, if yearly mean values of salinity and riverine discharge are used for the budget calculation [10, 13]. Nevertheless, Chen's [2] attempt is commendable for pointing out the seasonal contrast on the East China Sea shelf, which warrants a more careful study by taking into consideration of time-dependent terms in mass balance equations.

\section{REFERENCES}

11] Chan S.-Y., Circulation of the East China Sea, a numerical study, J. Oceanogr. Soc. Jap. 46 (1991) 273-295.

[2] Chen C.-T.A., The Kuroshio intermediate water is the major source of nutrients on the East China Sea continental shelf, Oceanol. Acta 19 (1996) 523-527.

[3] Chen C.-T.A., Ruo R., Pai S.-C., Liu C.-T., Wang G.T.-F., Exchange of water masses between the East China Sea and the Kuroshio off northeastern Taiwan, Cont. Shelf Res. 15 (1995) 19-39.

[4] Chuang W.-S., Liang W.-D., Seasonal variability of intrusion of the Kuroshio water across the continental shelf northeast of Taiwan, J. Oceanogr. 50 (1994) 531-542.

[5] Gong G.-C., Liu K.-K., Pai S.-C., Prediction of nitrate concentration from two end member mixing in the southern East China Sea, Cont. Shelf Res. 15 (1995) 827-842.

[6] Gong G.-C., Shiah F.-K., Liu K.-K., Chuang W.-S., Chang J., Effect of Kuroshio intrusion on the chlorophyll distribution in the southern East China Sea north of Taiwan during Spring, 1993, Cont. Shelf Res., 17 (1997) 79-94.

[7] Gordon D.G., Boudreau P.R., Mann K.H., Ong J.E., Silvert W.L., Snith S.V., Wattayacorn G., Wulff F., Yanagi T., LOICZ Biogeochemical Modelling Guidelines, LOICZ Reports \& Studies No.5 (1996) 96 p..

[8] Hall J., Smith S.V., Boudreau P.R., Report on the International workshop on continental shelf fluxes of carbon, Nitrogen and phosphorus, LOICZ Reports \& Studies NO. 9 (JGOFS Report No. 22), LOICZ Core Project Office, Texel, The Netherlands, 1996.
[9] Hsueh Y., Chern C.-S., Wang J., The intrusion of the Kuroshio across the continental slope northeast of Taiwan, J. Geophys. Res. 97 (1992) 14323-14330.

[10] Li Y.-H., Material exchange between the East China Sea and the Kuroshio Current, Terr. Atm. Oceanic Sci. 5 (1994) 625631.

[11] Liu K.-K., Gong G.-C., Lin S., Yang C.-Y., Wei C.-L., Pai S.C., Wu C.-K., The year-round upwelling at the shelf break near the northern tip of Taiwan as evidenced by chemical hydrography, Terr. Atm. Oceanic Sci. 3 (1992) 243-275.

[12] Liu K.-K., Iseki K., Chao S.-Y., Continental margin carbon fluxes, in: Hanson R.B., Ducklow H., Field J.G. (Eds.), The Dynamic Ocean Carbon Cycle, Cambridge Univ. Press (1998, in press).

[13] Nozaki Y., Kasemsupaya V., Tsubota H., Mean residence time of shelf water in the East China and Yellow Seas determinaed by ${ }^{228} \mathrm{Ra} /{ }^{226} \mathrm{Ra}$ measurements, Geophys. Res. Lett. 16 (1989) $1297-1300$.

[14] SCOR Report of the JGOFS/ LOICZ Task team on continental margin studies, JGOFS Report No. 16, Scientific Committee on Oceanic Research, Baltimore, 1994.

[15] Tang T.-Y., Yang Y.-C., Low frequency current variability on the shelf break northeast of Taiwan, J. Oceanogr. 49 (1993) 193-210.

[16] Wong G.T.-F., Pai S.-C., Liu K.-K., Liu C.-T., Chen C.-T.A., Variability of the chemical hydrography at the frontal region between the East China Sea and the Kuroshio northeast of Taiwan, Estuarine Coastal Shelf Sci. 33 (1991) 105-120. 